

\title{
From public to private safety regulation? The case of negotiated agreements in the French fresh produce import industry
}

\author{
Jean Marie Codron, M'hand Fares, Elodie Rouvière
}

\section{- To cite this version:}

Jean Marie Codron, M'hand Fares, Elodie Rouvière. From public to private safety regulation? The case of negotiated agreements in the French fresh produce import industry. International Journal of Agricultural Resources Governance and Ecology, 2007, 6 (3), pp.415-427. 10.1504/IJARGE.2007.012845 . hal-02656826

\section{HAL Id: hal-02656826 \\ https://hal.inrae.fr/hal-02656826}

Submitted on 30 May 2020

HAL is a multi-disciplinary open access archive for the deposit and dissemination of scientific research documents, whether they are published or not. The documents may come from teaching and research institutions in France or abroad, or from public or private research centers.
L'archive ouverte pluridisciplinaire HAL, est destinée au dépôt et à la diffusion de documents scientifiques de niveau recherche, publiés ou non, émanant des établissements d'enseignement et de recherche français ou étrangers, des laboratoires publics ou privés. 


\title{
From public to private safety regulation ? The case of negotiated agreements in the French fresh produce import industry
}

\author{
Codron, J.M. ; Fares, M. ; Rouvière, E. \\ UMR MOISA INRA, Campus Ensam/INRA, 2 place Viala, Montpellier 34 060, Cedex 1, France. \\ International Journal of Agricultural Resources, Governance and Ecology, vol. 6, $n^{\circ}$ 5, 2007, 415-427
}

\section{Introduction}

The growing number of crises related to food safety has led public authorities to strengthen food safety regulations, in particular in developed countries. The law increases the responsibility of the actors in the food supply chain and obliges them to monitor the safety of the products they market.

This article deals with the safety control devices on the French import markets for fresh fruit and vegetables for three reasons: i) the nature of the safety risk in the fruit and vegetables industry; ii) the specific legal status of the French importer; and iii) the original organisation of safety controls on the import markets. First, the safety risk in the fruit and vegetables sector demonstrates two particularities which make the analysis of safety control devices of great interest. On the one hand, the fruit and vegetables sector is primarily confronted with a problem of pesticide residues. Pesticides are used during production or post-harvest to treat fresh produce and residues may be found in or on the produce prior to consumption. There is, however, a lack of sound scientific proof concerning the potential risks related to the daily intake of fresh produce containing pesticides (Wilson and Otsuki, 2004). The pesticide risk can, therefore be qualified as being a "minor" risk in comparison to the pathogenic risk present in the meat and fish sectors. This qualification of risk can be explained by the very low probability of serious and immediate consequences for human health after consumption of fresh produce. On the other hand, the nature of the products makes safety controls difficult 
to implement. Fruit and vegetables are sensitive and perishable products and thus generally have short delivery deadlines which, more often than not, do not fit in with the time required for analysing pesticides.

Second, we undertake our analysis in the French import sector due to the particular legal status of French importers. The importer is the first supplier to introduce the product onto the market. He can, therefore, be compared to a producer and is responsible for the products which he brings into the country. He is liable under criminal law if the products do not satisfy the regulations in force. The importer is therefore confronted by a legal risk when he introduces products onto the national market.

Third, changes in food safety regulations have given rise to an original organisation of safety controls in the import markets. Since 1998, French importers of fresh fruit and vegetables have been obliged to undertake their own safety controls in firms. These controls aim to check that imported fruit and vegetables respect the Maximum Residue Limits (MRL) for pesticides defined by French law. In order to satisfy this new regulation, importers* on the two French import markets, located in Perpignan and Rungis, have established safety self-monitoring agreements with the public authorities.

These safety self-monitoring agreements are negotiated between the DGCCRF (General Service for Consumption, Competition and the Repression of Fraud.), the public authority responsible for safety controls in the import markets, and a group of importers. The original nature of these agreements is to be found in their organisation. The agreements are organised on the basis of a model which is not completely decentralised. The importers are not committed to the public authorities directly, but instead are responsible to their "representative body". The "representative body" is in turn responsible to the public authorities, acting on behalf of importers during negotiations. The central position of the 
“representative body” gives it the status of guarantor of the importers' commitment.

This article aims to analyse these safety self-monitoring agreements and to characterise the importers' incentives which might explain the emergence and development of these agreements. We have undertaken this analysis using the case of the self-monitoring safety agreement in force in Perpignan for which we have adopted a two-step approach. First, we attempt to characterise the incentive mechanisms involved in the agreement, basing our analysis on the literature concerning incentive schemes in teams (Okuno, 1984; Aoki, 1990; Greif 1994; Milgrom et al., 1990). We demonstrate that the theoretical conditions for implementing the system do not exist in the agreement. Second, we endeavour to characterise the incentive schemes outside the agreement by employing the analytical framework of voluntary approaches to food safety developed by Segerson (1999) and Venturini (2003). We thus demonstrate that alternative hypotheses must be put forward in order to characterise the importers' incentives to commit themselves to the agreement voluntarily and to provide the resources necessary for safety controls of imported fresh produce. The introduction of a third party, namely supermarkets, may create the incentives necessary for the adoption of voluntary approaches to food safety by firms upstream. The private incentives created by supermarkets are primarily incentives in terms of market access, sales volumes and reputation.

To the best of our knowledge, no research has yet considered the French case for products such as fresh fruit and vegetables which present a safety risk that is still not wholly understood (Wilson and Otsuki, 2004). However, the existing literature has given extensive coverage to the English case, the organisational consequences of regulatory change and, in particular, the implementation of the principle of "due diligence" via the "Food Safety Act" (cf. Hobbs and Kerr, 1992; Henson and Caswell, 1999; Loader and Hobbs, 1999; Holleran, Bredahl and Zaibet, 1999). According to the principle of “due diligence” downstream firms are fully liable. They must therefore check that the products they market are safe. To do so 
they must monitor the safety practices of their upstream suppliers. In the United Kingdom, this principle of liability has led modern retailers to create quality assurance schemes and to impose them on their suppliers for improved monitoring of their food supply (Henson and Hooker 2001; Holleran et al., 1999). Furthermore, most of this research has focussed on sectors where the risk can be qualified as "major" due to the immediate and serious consequences for consumers which may result from contamination (Northen, 2001).

The article is organised as follows: section 2 presents the agreement and analyses the internal incentives mechanisms with regard to its organisation; section 3 deals with the external incentives for importers which might help to explain the emergence and development of these new mechanisms; section 4 concludes.

\section{Self-monitoring safety agreement for the fresh produce import industry in Perpignan.}

Changes in the French food safety regulations are characterised by an increased involvement and responsibility of the private actors with regard to food safety controls. Since 1998, importers of fruit and vegetables have been responsible for safety controls within their firms and must therefore implement a system of self-monitoring. Safety self-monitoring is aimed at checking that the imported products satisfy the MRLs for pesticides defined by French law. The importer is, in fact, the first supplier to introduce the fresh produce onto the market and is held liable under criminal law if the fresh produce which he imports does not comply with the MRLs for pesticides. They can be held if fruit and vegetables tested are over the MRLs.

\subsection{Self-monitoring agreement: a case study.}

On the Perpignan market, the self-monitoring safety agreement has been drafted on the initiative of the importers, negotiated then approved by the public authorities. It is, then, a negotiated agreement between the public authorities and the importers aimed at enabling the importers to respect collectively their new obligations with regard to self-monitoring. It 
characterises the coordination between public and private actors in the process of drafting new regulations for safety controls and consolidates the wish of the two parts to cooperate. It can, therefore, be considered as a tool of co-regulation (Eijlander, 2005).

The organisation of the agreement is not based on an entirely decentralised model (cf. figure 1). The agreement comprises two sub-agreements. A first sub-agreement exists between the importers and their "representative body", while a second sub-agreement links the "representative body" to the public authorities. The importers do not commit directly to the public authorities. They first form a collective group and then commit to their "representative body”.

The importers committed to the agreement represent about $80 \%$ of the firms present on the market in Perpignan. The cost of committing to the agreement is twofold: the firms must pay a subscription fee of $1,000 €$ per year while at the same time allocating human and financial resources for implementing, monitoring and completing the safety self-monitoring. The firms who do not adhere to the agreement are either small firms which are new to the sector of activity, or large highly-organised firms. The former, for whom the safety aspect of the fresh produce is of secondary importance, find commitment to the agreement too costly whilst the latter already have their own provisions for safety self-monitoring.

The importers" "representative body" is an administrative organisation. The constituent 
members are not involved in the import sector. They are paid by the importers and therefore assume an administrative role of representing these importers. The central position of the "representative body" in the organisation of the agreement gives it the status of guarantor of the agreement. On the one hand, it is the spokesperson for the importers: the representative body negotiated the agreement with the public authorities on behalf of the importers. On the other hand, it is the dedicated contact for the public authorities and must therefore ensure close control of the importers' group. The "representative body" must, then, ensure that the importers undertake the safety self-monitoring and respect their commitment.

The DGCCRF is the public authority responsible for public safety controls on the import markets. Historically speaking, the mission of the public authorities was to control the public norms which were, more often than not, accompanied by sanctions. The introduction of the agreement has caused its function to change from that of controller to a more preventive role. In the agreement, the official control is a second-level control which consists of checking that the firms undertake their safety self-monitoring correctly. Implementing the agreement thus means that the delegation of the imported produce safety controls to the importers is official. For the public authorities, delegation of safety controls has two main objectives. First, the safety self-monitoring undertaken by the importers increases the number of controls on the market and thus facilitates an increase in the number of analyses undertaken. Second, it reduces the costs of public control by transferring the control and analysis costs to the importers. This transfer allows a reallocation of resources provided to public control in those sectors where the level of risk seems higher. In sectors such as the meat sector, public intervention is still inescapable and is related to the recent food outbreaks.

The agreement is a code of conduct for controlling the safety level of supplies, enabling importers as a group to satisfy the requirement of self-monitoring. The code of conduct, therefore, defines the procedure for collective safety self-monitoring. By adhering to the 
agreement, the importers undertake to: i) assign one person to quality control; ii) implement the common self-monitoring safety procedure; and iii) carry out laboratory analyses. The collective safety self-monitoring procedure is based on the principles of the HACCP method (Hazard Analysis Critical Control Point.). In light of the information available to them (production practices, relations with foreign suppliers, etc.), the importers must identify fruits and vegetables which might present an excess of MRLs in relation to pesticides used in production and post-harvest. At the start of the campaign, the importers define a sampling plan for fresh produce to be controlled and determine the number of analyses to be carried out during the campaign. Laboratory pesticide analyses must therefore be carried out on a regular basis. These pesticide analyses are costly and must be carried out for all produce provided for in the sampling plan. A standard multi-residues analysis costs more than $200 €$ for one sample of a given product. The fact that the importers form a group which adheres to the agreement enables them to take advantage of economies of scale. The agreement means that they can share both the costs of implementing self-monitoring in the firms and the cost of the analyses. The definition and negotiation of the safety self-monitoring procedure are common to all the importers in the group and the pesticide analyses are undertaken by a single laboratory at a preferential rate. The results of the analyses remain at the discretion of the importers. In the event of a safety anomaly, the importers must alert the "representative body" voluntarily, which then conveys the information to the public authorities. As long as the results are not over the MRL they do not have to report them. Moreover, in order to be cleared through customs when entering the French market, fresh produce must pass through a series of controls (customs, phytosanitary services and DGCCRF). Membership of the collective agreement allows importers to avoid the DGCCRF control and thus to save time.

The success of the agreement lies in the definition of the control and enforcement mechanisms which must force the importers to respect their commitment. In the agreement, 
these functions fall to the "representative body. The "representative body", ensures that the safety self-monitoring undertaken by the importers is realised. Monitoring is effected by means of random visits and reminders when the importers do not respect the established sampling plan. The mechanisms for enforcing the agreement rely on principles of exclusion. The representative body decides whether or not to exclude importers who do not undertake their safety self-monitoring. Exclusion can be temporary or permanent. Those importers who are excluded can no longer benefit from the advantages provided by the agreement: i) costsharing for the controls; ii) reduction of resources required in implementing the common procedure.

With regard to public control, the authorities made considerable concessions during the negotiation of the agreement. First, their controls have become a second-level control, that is, the authorities rely on the record-keeping of self-monitoring provided by the importers. Second, the frequency of official controls has been greatly reduced within the group. Third, in the event of an established safety anomaly, the authorities assume that the importers act in good faith. If the inspectors of the DGCCRF believe that the resources mobilised by the firms in the context of the safety self-monitoring are sufficient, the importer will not be held liable under criminal law. In this context, joining the agreement can be perceived as a means for the importers to reduce the scope of the controls of public norms within the group. It also allows them to reduce the extent of their own legal liability in the event of a safety issue.

The agreement, in its current organisational structure, poses a problem in terms of incentives, as we will see below. Implementing the self-monitoring safety agreement requires two conditions: first, the public authorities must ensure that the "representative body" carries out its control and enforcement functions; and second, the "representative body" must create sufficient incentives to make the collective discipline mechanisms effective within the group. 


\subsection{Internal incentive schemes in the self-monitoring agreement.}

To study the incentive question within the agreement, we compare the "representative body" to a supervisor of a team (the group of importers). This comparison leads us to consider the literature concerning incentive schemes in decentralised systems and, in particular, the approaches developed by Aoki and Okuno (Aoki, 1990; Okuno, 1984). Aoki (1990) establishes that two conditions exist in a team game with a supervisor so that each member of the team and the supervisor have an interest in complying with the rules of the agreement. The first condition concerns the supervisor's incentive while the second condition concerns the existence of an incentive mechanism within the team.

How to supervise the supervisor? The literature suggests two types of solution: either the implementation of a traditional incentive system or the introduction of a principle of supervisor responsibility. First, the implementation of a "traditional" incentive system assumes that there is the possibility of rewarding the supervisor when he controls his team efficiently and the desired level of effort within the group is achieved. However, the selfmonitoring agreement signed with the public authorities generates neither positive incentives (subsidies) nor negative incentives (taxes). Second, Aoki (1990) suggests the introduction of a principle of awareness of his responsibility by the supervisor. On the one hand, the supervisor can be "relieved" of his functions if the level of effort produced by the team does not reach the desired level. The introduction of such a principle assumes that the supervisor's effort is monitored alongside that of the team as a whole. This option has a cost and was not envisaged during the development and negotiation of the agreement. On the other hand, it should be possible to make the supervisor legally liable. If the team does not perform correctly, the supervisor should be held liable. While negotiating the agreement, the public authorities suggested introducing a principle whereby the representative body would have greater responsibility. This principle of responsibility was rejected because the threat appeared too 
strong for the "representative body" and it did not satisfy its participation constraints.

The second condition concerns the introduction of a collective discipline mechanism within the team. Each member of the team must, then, not only find an economic advantage in undertaking such an effort, but also be encouraged to maintain his place in the team. The literature concerning decentralised systems has developed this aspect, in particular by establishing that the existence of a mechanism of ostracism within the team can force members to respect their commitment (Okuno, 1984; Milgrom, North and Weingast, 1990, Greif, 1994). For this to be successful, it must be possible to identify free riding behaviour, a fact which requires the existence of a third party or system responsible for this function. The agreement provides for exclusion mechanisms and the enforcement of such mechanisms is the responsibility of the "representative body". We demonstrated above that the "representative body" is in no way encouraged to fulfil its role of controller. Just as the "representative body" is not encouraged to assume its responsibility, nor is it encouraged to fulfil its role of enforcement. Moreover, the representative body is not fully neutral. Thus, the collective discipline mechanisms cannot, then, be effective in light of the current agreement.

We have demonstrated that the theoretical conditions for implementing the system do not exist in the current agreement. The importers are encouraged neither to allocate resources for safety controls nor to commit themselves voluntarily to the agreement. Nor do the concessions made by the public authorities with regard to public controls, and in particular to reducing the extent of legal responsibility, appear to be credible incentive mechanisms. Indeed, on the import markets, public safety control is hindered by the gradual reduction of the budgets and personnel allocated to public control. For importers, the probability of their being liable in the event of a safety anomaly is low, at least in the current period. The same is true for importers who are not bound by the agreement. Commitment to the agreement cannot, then, be seen as a means of protection against legal risk. 
Commitment to the agreement as a protection against legal risk is a less-than-satisfactory explanation. However, changes in public intervention and an increase in the legal risk for importers could occur in the long term. For example, if French consumer associations become more active on such safety issues as they are in some Northern European countries, they could exert more pressure on the legal system. In its current state, the agreement does not create incentives and we have to seek for other incentives in the short term which could explain the voluntary adhesion of importers to the agreement and the respect for their commitments. To answer this question, we turn to the literature on voluntary approaches to food safety.

\section{Voluntary approach to food safety: new insights.}

\subsection{The safety self-monitoring agreement: a voluntary approach to food safety?}

Numerous papers have analysed the introduction of voluntary approaches in an environmental context (cf. Khanna, 2001 for a review of the literature). In this context, voluntary approaches aim to introduce protective measures to preserve the environment through auto-regulation by the firms (Segerson and Miceli, 1998). In the field of food safety, voluntary approaches are the measures taken by firms with a view to increasing or controlling the safety of the products they market. Recently, certain authors have analysed the emergence of voluntary approaches to food safety (Segerson, 1999; Venturini, 2003). In this section, we will refer to these researches to characterise the external incentives for importers which could help us to explain their voluntary commitment to the agreement.

The self-monitoring safety agreement corresponds to one of the three broad categories of voluntary approaches identified in the literature: i) unilateral initiatives, ii) negotiated agreements, iii) non-obligatory public programmes. They differ as to the extent of the public authorities' commitment to their implementation (Khanna, 2001). The first category is that of 
unilateral initiatives. These involve measures taken by firms in response to the demand or pressure of the market in which the regulator does not intervene. The second category is that of negotiated agreements. These are agreements which characterise a bilateral commitment between the firms on the one hand and the public authorities on the other with regard to the definition and negotiation of the new protective measures to be introduced. The third category is that of public programmes introduced by the public authorities. These programmes are nonobligatory and the firms have the option of participating or not.

The research concerning voluntary approaches to food safety primarily considers the decision of firms to adopt such safety measures (Segerson, 1999; Venturini, 2003; Noelke and Caswell, 2000; Caswell, Bredahl and Hooker, 1998). Sergerson (1999) provides a decisionmaking model where, faced with the regulator, the firm opts to implement voluntary safety measures or to remain passive. If the firm remains passive, the regulator may impose the introduction of mandatory measures. Segerson hypothesises that a voluntary system is less costly to implement than a mandatory system. She shows that a strong mandatory threat (i.e. a high probability of a more costly system being imposed) is a necessary and sufficient condition for firms to adopt safety measures voluntarily. However, by relaxing the assumption concerning costs, Venturini (2003) demonstrates that the mandatory threat is no longer a sufficient condition for the adoption of voluntary measures to ensure food safety. The firm must be able to promote or value the voluntary nature of its initiative with the consumer. Furthermore, Venturini adds that, as the safety quality of produce is a credence attribute, the firm needs to promote its initiative to consumers indirectly. For example, introducing independent certification, supported by the government, should serve to increase the credibility of voluntary approaches vis-à-vis the consumers.

In the agreement, the theoretical conditions for adopting voluntary approaches to food safety suggested in the literature above do not exist. First, the mandatory threat is weak. As we have 
seen before, the resources allocated to public control in the fresh produce sector are diminishing. Thus, the definition and imposition of a more stringent system of control are highly unlikely. In addition, the conditions for promoting the effort vis-à-vis the consumers are absent. First of all, the importer is not in direct contact with the consumers, most volumes are bought by the supermarkets. Second, promotion vis-à-vis the consumers is difficult to envisage with regard to the safety attributes of fruit and vegetables, except for organic produce which is still a "niche” market. In France, firms which communicate concerning the attributes of a product must provide proof of their claims. They are severely punished under criminal law in the event of false or unfounded claims. As the cost of proof concerning fresh fruit and vegetables is high, sellers generally refrain from communicating directly with regard to pesticide residues (Codron et al, 2005).

In light of the absence of a strong mandatory threat, and taking into account the literature studied, we should conclude that it is impossible to implement the voluntary commitment of importers to the agreement. The question of incentives for importers therefore remains unanswered.

\subsection{New proposals for voluntary approaches to food safety.}

We underline here the interest in changing our mind in analysing the decision of firms to adopt voluntary approaches within the supply chain. We should indeed consider that firms do not only take decisions with regard to the regulator, but also to private firms operating downstream. Alternative hypotheses to those suggested by Segerson (1999) and Venturini (2003) should thus be put forward to characterise firms' incentives to adopt voluntary safety measures within the supply chain. To the best of our knowledge, only a small number of papers have highlighted the impact of introducing a quality management system within the supply chain. Noelke and Caswell (2000), for example, suggest a model which identifies the 
interactions relating to the introduction of these systems in a simplified supply chain and to the consumer interface. Caswell, Bredahl and Hooker (1998) suggest a model which introduces the costs and benefits relative to the introduction of these systems at firm level. However, we have just established that the analysis of firms' decisions to adopt voluntary approaches cannot be generalised and thus specified depending on the firm's position in the supply chain.

Other research (Codron et al, 2005) shows that the incentive may come not from the consumer but from the supermarkets. The latter have an interest in strengthening food safety controls carried out by the state through the application of their own methods. One of the ways of implementing this private control is to give the supplier strong incentives to undertake these controls himself. With regard to fruit and vegetables, delegation of safety controls upstream is possible in so far as the effort made to monitor the residues can be undertaken at different levels in the chain. The introduction of a third party, namely the supermarkets, can thus create the incentives necessary for the adoption of voluntary approaches to food safety by firms upstream.

For firms upstream, the private incentives created by the supermarkets are primarily incentives in terms of market access, sales volumes and reputation. These incentives thus characterise the commercial risk faced by the supermarkets' suppliers. Indeed, the supermarkets represent a real commercial stake for firms in the food-supply chain because they are the dominant outlets for selling large volumes. The incentives generated by the supermarkets can also be positive. They might take the form of price premiums paid to the suppliers. The supermarkets can then attempt to transfer these premiums to the consumers by using private label strategies to promote or to value indirectly the safety attributes of products. The commercial risk and a possible promotion of voluntary approaches to food safety within the supply chain are important and should be considered in theoretical analyses. 
Today, for fruit and vegetables, the safety aspect of fresh produce is still not a predominant factor in the commercial relationships between the suppliers and the French supermarkets (Martinez and Poole, 2004). The emergence of a self-monitoring safety agreement could, then, be explained by an attempt on the part of importers to offer the supermarkets a collective safety control system for imported fruit and vegetables. The implicit objective of the importers is thus to make the collective self-monitoring safety agreement credible for the supermarkets. Northen (2001) notes the same effect among English meat producers. The aim of implementing a collective system of quality control directed by producers was to act as a credible sign of the food safety attributes of the products vis-à-vis the English supermarkets. Henceforth, to maintain their market access, the importers must make sure that their collective self-monitoring procedure is credible in complying with the supermarkets' private safety standards. The emergence and development of the self-monitoring agreement could be considered as an attempt by importers to position themselves vis-à-vis the supermarkets and to protect themselves against commercial risk. The importers have, then, foreseen the role that the safety aspect of fruit and vegetables should play in the future in their commercial relations with the French supermarkets.

The commercial risk ${ }^{* *}$ represented by the supermarkets therefore constitutes a strong, private incentive against which the firms try to protect themselves and this can explain the adoption and the development of safety voluntary approaches within the food supply chain. The incentives within the supply chain are not the same as those in the analyses of the firm/consumer interface. For firms upstream in the supply chain, there is a need to consider both the commercial risk and the legal risk. Firms are usually more adverse to commercial risk than to legal risk. 


\section{Conclusion}

In this article, the analysis of the Perpignan agreement allows us to demonstrate two results. First, the organisation of the agreement requires the introduction of internal incentive mechanisms so that each member respects his commitment. However, there is no means of implementing a collective discipline mechanism within the group. The fact that the "representative body" has no legal responsibility means that the latter is in no way encouraged to fulfil its functions of control and enforcement. Furthermore, commitment to the agreement does not appear to be a means for the importers to protect themselves against legal risk. The probability of being held liable in the event of a safety anomaly is low, irrespective of whether the importers adhere to the agreement or not. The legal risk is too insignificant in the current period for importers to care about protecting themselves by voluntarily committing to the agreement and allocating resources for safety controls.

Second, by suggesting alternative hypotheses to those presented by Segerson (1999) and Venturini (2003), we demonstrate that the commitment of the importers to the agreement can represent a means of protecting themselves against commercial risk in their relations with the supermarkets, their most important customers. The importers thus initiated the agreement in order to offer distributors a credible collective system for controlling the safety of imported fruit and vegetables. Commitment to the agreement is a means of satisfying the increasing demands of the latter. In this way, we emphasise the interest in considering both commercial risk and legal risk in the firms' decision to adopt voluntary approaches to food safety within the supply chain.

To conclude, the agreement has considerable consequences for the French import sector. On the one hand, the agreement has allowed a highly-fragmented sector to become more structured. On the other hand, it has facilitated the organisation of a group of importers 
through the emergence of a cooperation procedure in a highly-competitive sector. The agreement is, then, considered by importers as an opportunity granted by the state to create a pool of importers capable of offering a collective system of food safety controls which they will endeavour to make credible vis-à-vis the supermarkets. Indeed, at this level, the major issue is the credibility of the agreement vis-à-vis the supermarkets. Today, the supermarkets act as private regulators which promote food safety controls in the supply chain through their own incentives and sanctions.

Further research will be necessary to assess whether this new form of regulation is a substitute for or a complement to public regulations. At present, it would appear to be a substitute. Indeed, both ex-ante public control and ex-post legal risk seem to have little effect on the decisions of private actors. A change in public intervention could occur for instance if French consumer associations were to become more active bodies, thereby exerting more pressure on the legal system as is already the case in some Northern European countries such as the Netherlands and the United Kingdom.

\section{Acknowledgments:}

The authors ARE VERY GRATEFUL TO Céline Bignebat and three anonymous referees for their comments and very helpful suggestions. This research was supported by the Ecoponics program (www.ecoponics.de) a project of the European Union under the INCO-MED2 (Shared Cost Action) Research Programme within the 5th framework programme (FP5RTD) (www.cordis.lu/fp5).

\section{References:}

Aoki, M. (1990) 'Toward an Economic Model of the Japanese Firm.' Journal of Economic Literature, XXVIII (1), pp.1-14.

Caswell, J., Bredahl M. and Hooker N. (1998) 'How Quality Management Metasystems 
Affecting the Food Industry.’ Review of Agricultural Economics, 20(2), pp. 547-557.

Codron J.M., Giraud Heraud, E. and Soler, L.G. (2005), 'Minimum Quality Standards, Premium Private Labels, and European Meat and Fresh Produce Retailing', Food Policy, 30(3), pp 270-283.

Eijlander, P. (2005) 'Possibilities and constraints in the use of self-regulation and coregulation in legislative policy. Experiences in the Netherlands-Lessons to be learned for the EU?' Electronic Journal of Comparative Law, 9(1), pp.1-8.

Greif A., (1994) 'Contract Enforceability and Economic Institutions in Earlier Trade: The Maghribi Traders’ Coalition’. American Economic Review, 83(3), pp.525-548.

Henson, S. and Caswell, J. (1999) 'Food Safety Regulation: An Overview of Contemporary Issues.’ Food Policy, 24 (6), pp.589-603.

Henson, S. and Hooker, N. (2001) "Private Sector Management of Food Safety: Public Regulation and the Role of Private Controls." The International Food and Agribusiness Management Review, Vol. 4, No.1, pp. 7-17.

Hobbs, J. and Kerr, W. (1992) 'Costs of Monitoring Food Safety and Vertical Coordination in Agribusiness: What Can Be Learned from the British Food Safety Act 1990?' Agribusiness, 8(6), pp.575-84.

Holleran, E., Bredahl, M. E. and Zaibet, L. (1999) 'Private Incentives for Adopting Food Safety and Quality Assurance.’ Food Policy, 24(6), pp. 669-83.

Khanna, M. (2001) 'Non Mandatory Approaches to Environmental Protection.' Journal of Economic Surveys, 15(3), pp.391-424.

Loader, R. and Hobbs, J. (1999) 'Strategic Responses to Food Safety Legislation.' Food Policy, 24 (6), pp.685-706.

Garcìa Martinez, M. and Poole N. (2004) 'The development of private fresh produce safety standards: implications for developing Mediterranean exporting countries', Food Policy, 29(3), pp.229-255.

Milgrom P.R., North CD. and Weingast B.R. (1990) 'The Role of Institutions in the Revival of Trade: The Law Merchant, Private Judges, and the Champagne Fair', Economics and Politics, 2(1), pp.1-23.

Noelke, C. M. and Caswell J. (2000) "A Model of the Implementation of Quality Management Systems for Credence Attributes," Paper selected at the AAEA Annual Meeting. Tampa, Florida, 28p.

Northen, James R. (2001) 'Using Farm Assurance Schemes to Signal Food Safety to Multiple Food Retailers in the U.K.' The International Food and Agribusiness Management Review, 4(1), pp.37-50.

Okuno, M. (1984) 'Corporate Loyalty and Bonus Payments: An Analysis of Work Incentives in Japan.' In M. Aoki (Ed): The Economic Analysis of the Japanese Firm. North Holland: Elsevier Publishers, pp.387-411. 
Segerson, K. and Miceli, T. (1998) 'Voluntary Environmental Agreements: Goods or Bads News for Environmental Protection?' Journal of Environnemental Economics and Management, 36, pp.109-30.

Segerson, K. (1999) 'Mandatory Versus Voluntary Approaches to Food Safety.' Agribusiness, 15(1), pp.53-70.

Venturini, L. (2003) 'Public Regulation and Voluntary Approaches to Food Safety Credence Good' In G. Schiefer, Rickert U. (Eds): Quality Assurance, Risk Management and Environmental Control in Agriculture and Food Supply Networks. Bonn: Universität BonnILB, Germany, 82nd Eaae Seminar, pp.265-69.

Valceschini, E. and Nicolas, F. (1995) 'La dynamique économique de la qualité agroalimentaire’.p.15-37 In Valceschini, E. et Nicolas F (Eds) : Agro-alimentaire : une économie de la qualité, Paris : INRA : Economica.- 433p.

Wilson J. and Otsuki, T. (2004) 'To spray or not to spray: pesticides, banana exports, and food safety.', Food Policy, 29(2), pp.131-146.

\section{Notes:}

* Importers who are members of the collective agreements are not only located in Rungis and Perpignan but nevertheless depend on the collective agreements with Perpignan and Rungis as registration centres.

** We distinguish commercial risk from legal risk for two reasons. First, these two risks are not linked. The legal risk depends on public control and on the ability of public authorities to monitor and then sanction firms which fail. The commercial risk relies on a private contract between firm and retailer. The retailer can undertake safety tests; if the firm fails it faces a commercial sanction but never legal proceedings. Second, if a firm fails a public test, the customer (the retailer) is never informed, either by the public agency or by the firm. 